\title{
Congenital heart block: evidence for a pathogenic role of maternal autoantibodies
}

\author{
Aurélie Ambrosi and Marie Wahren-Herlenius*
}

\begin{abstract}
During pregnancy in autoimmune conditions, maternal autoantibodies are transported across the placenta and may affect the developing fetus. Congenital heart block (CHB) is known to associate with the presence of anti-Ro/SSA and anti-La/SSB antibodies in the mother and is characterized by a block in signal conduction at the atrioventricular (AV) node. The mortality rate of affected infants is $15 \%$ to $30 \%$, and most live-born children require lifelong pacemaker implantation. Despite a well-recognized association with maternal anti-Ro/La antibodies, CHB develops in only 1\% to $2 \%$ of anti-Ro-positive pregnancies, indicating that other factors are important for establishment of the block. The molecular mechanisms leading to complete AV block are still unclear, and the existing hypotheses fail to explain all aspects of CHB in one comprehensive model. In this review, we discuss the different specificities of maternal autoantibodies that have been implicated in CHB as well as the molecular mechanisms that have been suggested to operate, focusing on the evidence supporting a direct pathogenic role of maternal antibodies. Autoantibodies targeting the $52-\mathrm{kDa}$ component of the Ro antigen remain the antibodies most closely associated with $\mathrm{CHB}$. In vitro experiments and animal models of CHB also point to a major role for anti-Ro52 antibodies in CHB pathogenesis and suggest that these antibodies may directly affect calcium regulation in the fetal heart, leading to disturbances in signal conduction or electrogenesis or both. In addition, maternal antibody deposits are found in the heart of fetuses dying of $\mathrm{CHB}$ and are thought to contribute to an inflammatory reaction that eventually induces fibrosis and calcification of the AV node, leading to a complete block. Considering that CHB has a recurrence rate of 12\% to 20\% despite persisting maternal autoantibodies, it has long been clear that maternal autoantibodies are not sufficient for the establishment of a complete CHB, and efforts have been made to identify additional risk factors for this disorder. Therefore, recent studies looking at the influence of genetic and environmental factors will also be discussed.
\end{abstract}

Autoantibody-associated congenital heart block (CHB) is a passively acquired autoimmune condition in which maternal autoantibodies are thought to initiate conduction disturbances in the developing fetal heart. Hallmarks of autoantibody-associated $\mathrm{CHB}$ are the presence of immune complex deposits, inflammation, calcification, and fibrosis in the fetal heart and a block in signal conduction at the atrioventricular (AV) node in an otherwise structurally normal heart. Clinical signs most commonly develop during weeks 18 to 24 of pregnancy. Although autoantibody-associated CHB may initially be detected as a first- or second-degree AV block, most of the affected pregnancies will present with fetal bradycardia in third-degree (complete) AV block, and ventricular

*Correspondence: marie.wahren@ki.se

Rheumatology Unit, Department of Medicine, Karolinska Institutet, 17176 Stockholm, Sweden rates typically are between 50 and 70 beats per minute. A complete AV block is a potentially lethal condition associated with significant morbidity, and the majority of affected children require permanent pacemaker implantation [1-3].

Whereas complete AV block is the major manifestation of autoantibody-associated CHB, other cardiac abnormalities are increasingly being recognized. Transient first-degree AV block has been shown to occur in up to $30 \%$ of fetuses of mothers with anti-SSA/Ro 52-kDa antibodies [4]. The presence of sinus bradycardia [5-7] and prolongation of the QTc interval $[8,9]$ have also been reported; however, these findings were not replicated in another recent study [10]. Endocardial fibroelastosis and cardiomyopathy have been reported in both the presence and absence of conduction abnormalities and are associated with a poor prognosis [11-14].

Since the initial observation that sera of mothers of children with CHB contain anti-SSA/Ro antibodies, the association between maternal autoantibodies and CHB 
has been extensively studied. Most of the current knowledge comes from the comparative analysis of sera of women with affected or healthy infants, and additional information has been generated through the use of animal models. Nevertheless, the pathogenic molecular mechanisms of autoantibody-associated $\mathrm{CHB}$ remain unclear. Because the risk for CHB in an anti-SSA/Ropositive pregnancy is only $1 \%$ to $2 \%[5,15]$, the need for a better marker not only for pregnancies at risk but also for the identification of other risk factors influencing the development of $\mathrm{CHB}$ is still important. This review will give a broad perspective of the maternal antibodies that have been associated with $\mathrm{CHB}$ and then will focus on the antibody specificities that have been more specifically implicated in the pathogenesis of the disease through in vitro and in vivo studies. The current hypotheses for autoantibody-associated CHB development will be discussed with an emphasis on the potential molecular targets for maternal antibodies in the fetal heart before mentioning other risk factors that have recently come to light.

\section{Congenital heart block and autoantibody-associated heart block}

Before a review of the evidence implicating maternal antibodies in the pathogenesis of $\mathrm{CHB}$, it may be necessary to define more precisely the patient population discussed in this review. Heart block developing during fetal life is most commonly associated with either congenital malformations or the presence of autoantibodies in the mother. More rarely, CHB may occur following viral infection or drug treatment or be diagnosed without any identifiable cause. In the last case, it is of course possible that the mother carries autoantibodies but at a level too low for detection. Heart block may also develop during infancy or early childhood, and to distinguish true CHB cases from these later-onset heart block cases, a new definition for $\mathrm{CHB}$ has been proposed; according to this definition, heart block is considered congenital if diagnosed in utero or during the first 27 days of life [16]. This review focuses on autoantibody-associated heart block, which develops in the fetal heart in the absence of any major structural malformation and in the presence of maternal autoantibodies. Autoantibody-associated heart block has been found to fulfill the criteria for $\mathrm{CHB}$ in the vast majority of cases in two independent studies $[17,18]$. For readability purposes, we will refer to autoantibodyassociated heart block as $\mathrm{CHB}$ in the rest of the review.

\section{Maternal autoantibodies associated with heart block Anti-Ro/SSA and -La/SSB autoantibodies}

Since the early ' 80 s, it has been known that the development of CHB is closely associated with the presence of maternal autoantibodies that are most commonly found in the rheumatic autoimmune diseases Sjögren's syndrome (SS) and systemic lupus erythematosus (SLE) $[19,20]$. However, CHB appears to be more specifically linked to the presence of maternal anti-Ro/SSA and anti$\mathrm{La} / \mathrm{SSB}$ autoantibodies rather than to maternal diagnosis, as the mother of an affected child may be asymptomatic $[2,21,22]$. In the late ' 80 s and early '90s, the Ro/SSA autoantigen was shown to consist of two unrelated proteins, Ro52 and Ro60 [23,24], and subsequent studies of $\mathrm{CHB}$ association with maternal antibodies have sought to determine the serum profile of mothers of affected children in regard to the three components Ro52, Ro60, and La. Although the data vary among the different studies (depending on the method used for antibody detection, the enrolment criteria for pregnancies, and the definition of $\mathrm{CHB}$ ), most of the attempts demonstrate that anti-Ro, and especially anti-Ro52, antibodies are present in a high proportion of mothers of children with CHB [25-28]. This finding was further confirmed recently in a population-based study in Sweden, where the serum of $95 \%$ and $63 \%$ of autoantibody-positive women who had a child with heart block displayed reactivity toward the Ro52 and Ro60 proteins, respectively [29].

As anti-Ro60 antibodies are most often found together with anti-Ro52 antibodies, it is difficult to assess the individual contribution of the former to the development of CHB. In addition, most studies still rely on clinical assays that do not distinguish between Ro52 and Ro60 to investigate the presence of anti-Ro antibodies in maternal sera. In the study by Salomonsson and colleagues [29], anti-Ro60 antibodies were found in $63 \%$ of autoantibodypositive mothers of children with $\mathrm{CHB}$; however, these antibodies were present in the absence of anti-Ro52 antibodies in only $3 \%$ of mothers of children with CHB.

In contrast to the association of anti-Ro antibodies to $\mathrm{CHB}$, the association of anti-La antibodies to CHB is still a matter of debate. In two studies, the levels of anti-La antibodies in mothers of children with cutaneous neonatal lupus erythematosus were found to be higher than in women giving birth to a child with CHB [30,31]. However, another study suggested that the risk for CHB was increased in the presence of anti-La antibodies [32]. The current consensus is that antibodies to Ro60 and La may contribute to the inflammatory reaction that leads to AV block but that CHB may develop in their absence.

\section{Other autoantibodies}

Given the low risk for fetal heart block in an anti-Ropositive pregnancy, the presence of maternal antibodies targeting antigens other than Ro/SSA and La/SSB and potentially associating with $\mathrm{CHB}$ has been suggested. A few candidates have been investigated; however, such studies remain few and often do not involve enough cases to demonstrate a reliable association between the presence 
of antibodies and pregnancy outcome. Antibodies to calreticulin, a protein involved in calcium storage, have been found more frequently in sera from mothers of children with $\mathrm{CHB}$ than in sera from mothers of healthy children [33]. Antibodies recognizing the M1 muscarinic acetycholine receptor have also been associated with the development of $\mathrm{CHB}$, and in vitro studies suggest a functional role for these antibodies through binding to and interfering with the function of their target in the neonatal myocardium $[34,35]$. The presence of antibodies to calreticulin and to the M1 muscarinic acetycholine receptor, however, has not been investigated in other larger cohorts, and the relevance of the in vitro findings in heart block pathogenesis remains uncertain. Antibodies recognizing a cleavage product of $\alpha$-fodrin have been proposed as an additional serological marker for CHB [36]; however, these antibodies are often found in patients with SS [37], a condition in which anti-Ro antibodies are also often prevalent, raising the possibility that the association of anti- $\alpha$-fodrin antibodies with $\mathrm{CHB}$ reflects only the close relation between $\mathrm{CHB}$ and anti-Ro antibodies. The reactivity of sera from mothers of children with $\mathrm{CHB}$ to the $\alpha$-enolase protein was recently evaluated following a report of cross-reactivity of specific anti-Ro52 antibodies to this protein [38]. However, only a small proportion of $\mathrm{CHB}$ sera were positive, indicating that these antibodies may represent only a subset of mothers at risk [39]. Similarly, reactivity to the $\alpha 1 D$ calcium channel subunit and to the serotoninergic 5-hydroxytryptamine (5- $\left.\mathrm{HT}_{4}\right)$ receptor was found in sera from mothers of children with CHB; however, such reactivity was limited to about $14 \%$ and $16 \%$ of the tested mothers, respectively $[40,41]$.

\section{Fine specificity of anti-Ro52 antibodies associated with congenital heart block}

The close correlation between maternal anti-Ro52 antibodies and $\mathrm{CHB}$, added to the fact that only $1 \%$ to $2 \%$ of children born to anti-Ro-positive women develop heart block, has prompted a search for a specific profile that is within the pool of maternal anti-Ro52 antibodies and that would be a better marker for pregnancies at risk. In a study by Fritsch and colleagues [27], antibodies toward the Ro52 peptides comprising amino acids (aa) 107 to 122 and 277 to 292 were found at a higher frequency in mothers of children with $\mathrm{CHB}$ in comparison with mothers of healthy children; however, this was true only for mothers with SLE but not for asymptomatic mothers or those with SS. This suggests that the specificities identified in this study may correspond to only a small and defined group of mothers at risk, as asymptomatic women or women with SS actually represent a much larger proportion of $\mathrm{CHB}$ pregnancies [2]. Elevated levels of antibodies toward additional Ro52 peptides (aa 1 to 13 and aa 365 to 382) were also reported in the same study in SLE mothers during the risk period for CHB (18 to 30 weeks of pregnancy).

Dominant epitopes within the central part of the Ro52 protein have been described in the context of SLE and SS $[42,43]$, and epitope mapping using overlapping peptides covering this region revealed a significant association of maternal antibodies toward aa 200 to 239 of Ro52 (denoted p200) and the risk for CHB [26,44]. In a prospective study of anti-Ro52-positive women during weeks 18 to 24 of pregnancy, maternal antibodies to Ro52/p200 were shown to correlate to longer AV time intervals in fetuses [45]. In addition, serum reactivity to the p200 peptide was found in 60\% (53 out of 88) of anti-Ro52positive women who had given birth to a child with $\mathrm{CHB}$ in a Swedish cohort of CHB families [29]. It is possible that the presence of anti-p200 antibodies, even at low levels, is important in the initiation of AV conduction disturbances, as is suggested by studies in animal models (discussed below).

Although at present there is no unique antibody profile characterizing the mothers of children with $\mathrm{CHB}$, antiRo52 antibodies seem to remain the maternal autoantibodies that correlate the most to $\mathrm{CHB}$ development. However, given the low penetrance of the condition in anti-Ro-positive pregnancies, it is possible that not only the presence or fine specificity but also the levels of maternal anti-Ro52 antibodies are of importance in predicting fetal outcome. This was suggested in a study by Salomonsson and colleagues [26] and was supported by the recent findings of Jaeggi and colleagues [31], who found that cardiac conduction disturbances are associated with moderate to high levels of anti-Ro antibodies but not with low levels in a large cohort of children born to anti-Ro-positive mothers.

\section{Clues to congenital heart block pathogenic mechanisms from experimental models}

Direct evidence for a pathogenic role of maternal antiRo/La antibodies and especially anti-Ro52 antibodies in $\mathrm{CHB}$ comes from experimental studies of heart block, both in vitro and in vivo. The presence of anti-Ro antibodies in the cardiac tissue of fetuses dying of $\mathrm{CHB}$, together with deposition of complement, fibrosis, and calcification, was demonstrated over 20 years ago by several groups [46-48], providing the first link between maternal antibodies and pathogenesis of heart block by placing the antibodies at the site of injury. Of note, antibodies, complement, and signs of fibrosis and calcification were observed not only at the AV node but also in the entire myocardium, suggesting the potential involvement of maternal autoantibodies in other cardiac manifestations of $\mathrm{CHB}$, such as sinus bradycardia, cardiomyopathy, and QTc prolongation. 
In vitro studies performed in the late '90s and based on rat or human hearts isolated with the Langendorff technique demonstrated a direct pathogenic role of antibodies from mothers of children with $\mathrm{CHB}$, as perfusion of hearts with maternal IgG containing anti-Ro and anti-La antibodies induced bradycardia and complete AV block within 15 minutes [49,50]. Affinity-purified anti-Ro52 antibodies induced the same effects, showing the individual pathogenic potential of anti-Ro52 antibodies. Similar results were obtained in Langendorffperfused rabbit hearts exposed to anti-Ro/La antibodies purified from mothers of children with CHB [51,52]. Evidence for the pathogenicity of anti-Ro/La antibodies in vivo has been gathered from animal models based on passive transfer of antibodies or active immunization of females before gestation (Table 1) and is reviewed below.

\section{Immunization-based models of congenital heart block}

Active models of $\mathrm{CHB}$, in which female rats, mice, or rabbits are immunized with a particular antigen before gestation, make it possible to investigate the pathogenic potential of antibodies toward Ro52, Ro60, or La separately. Miranda-Carus and colleagues [53] showed that immunization of BALB/c mice with Ro60 or La led to the development of first-degree AV block in 19\% and $7 \%$ of the offspring, respectively, and similar results were observed in $\mathrm{C} 3 \mathrm{H} / \mathrm{HEJ}$ mice by Suzuki and colleagues [54]. In the study by Miranda-Carus [53], immunization of BALB/c mice with the human or mouse Ro52 protein induced first-degree AV block in only $9 \%$ of the offspring, whereas Boutjdir and colleagues [50] demonstrated a $25 \%$ incidence in the same model. Both studies reported higher degrees of AV block but at a lower frequency (3.5\% to $10 \%$ of $\mathrm{AV}$ block II/III). Immunization of rats with the human Ro52 protein led to the development of first-degree AV block in $10 \%$ to $45 \%$ of the pups, depending on the strain [55]. Immunization of rabbits with the human Ro52 protein also induced first-degree AV block in $12 \%$ of the offspring, and the authors reported a large number of neonatal deaths, which might have been related to higherdegree blocks; however, no histological evaluation of neonatal hearts was performed to support this hypothesis [56].

In an attempt to narrow the specificity of the anti-Ro52 antibodies inducing heart block in vivo, Salomonsson and colleagues [45] immunized DA (Dark Agouti) rats with the Ro52/p200 peptide and observed a 19\% incidence of first-degree AV block in the offspring. Immunization of mice with a recombinant Ro52 $\beta$ protein (Ro52 isoform lacking exon 4) induced first-degree AV block in $12 \%$ and AV block II/III in about $6 \%$ of the pups [53]; however, the relevance of these findings is uncertain as the endogenous protein has never been detected in humans or rodents, despite a report of Ro52 $\beta$ mRNA expression in the fetal human heart [57].
Antibody transfer-based models of congenital heart block Often, animal models of autoimmune diseases are based on immunization with a specific antigen (for example, experimental autoimmune encephalomyelitis for multiple sclerosis or collagen-induced arthritis). However, these models present an inherent variability as they rely on the immune response of each immunized animal. Many factors, such as genetic differences, age, or mode of immunization, may influence the outcome. In the context of $\mathrm{CHB}$, these limitations are all the more relevant considering that induction of disease depends on the antibody response elicited in the mother and that maternal major histocompatibility complex (MHC) has been shown to be of importance in the generation of pathogenic antibodies in CHB [55]. Therefore, the use of models in which antibodies are injected directly into the female during gestation provides an advantage in that the specificity and amount of antibodies transferred in the mother are known.

In a study by Mazel and colleagues [58], transfer of affinity-purified anti-Ro/La antibodies from two mothers of children with $\mathrm{CHB}$ into pregnant female BALB/c mice induced first-degree AV block in $47 \%$ to $90 \%$ of the offspring, depending on the day of gestation at which the injection was performed. Sinus bradycardia was also observed, albeit in a somewhat smaller proportion of pups. However, the use of a mixture of anti-Ro and antiLa antibodies in this study did not allow the precise identification of the antibody specificity contributing to the development of heart block. To address this issue, we have established a heart block model based on the transfer of anti-Ro52 monoclonal antibodies during gestation. Using this model, we observed that anti-Ro52 antibodies specific for the p200 part of the protein induced AV block in the offspring but that antibodies targeting other domains of Ro52 did not [59]. In addition, anti-Ro52 p200 antibodies were shown to disturb calcium homeostasis in cultured neonatal cardiomyocytes, supporting a pathogenic role for anti-Ro52 p200 antibodies in CHB. It is worth noting that first-degree AV block developed in $100 \%$ of the rat pups exposed to the antip200 monoclonal antibodies in utero but that only $19 \%$ of pups born to females immunized with the Ro52/p200 peptide were shown to develop AV block in a previous study. These results highlight the reproducibility of a passive transfer model compared with the use of immunization to induce CHB. Of note, the low penetrance of the condition and the lack of induction of complete AV block in animal models indicate that, as is the case of humans, other factors are required to allow the establishment of complete CHB.

\section{Targets of maternal antibodies in the fetal heart}

Despite the observation of a direct role for maternal antibodies in inducing AV block both in vitro and in vivo, 


\begin{tabular}{|c|c|c|c|c|}
\hline Inducing factor & Species (strain) & $\begin{array}{l}\text { roportion of AVB, } \\
\text { percentage }^{\mathrm{a}}\end{array}$ & $\begin{array}{l}\text { AVB II/III, } \\
\text { percentage }^{\mathrm{a}}\end{array}$ & Reference \\
\hline \multicolumn{5}{|c|}{ Antibody transfer during gestation (specificity/antigen) } \\
\hline Ro52 and Ro60 & Mouse (BALB/C) & $47-100$ & 0 & Mazel, et al. [58] (1998) \\
\hline Ro52/p200 (aa 200-239) & Rat (DA) & 100 & 0 & Ambrosi, et al. [59] (2012) \\
\hline Ro52/N- or C-terminal & Rat (DA) & 0 & 0 & \\
\hline \multicolumn{5}{|c|}{ Immunization before gestation (specificity/antigen) } \\
\hline Ro52 & Mouse (BALB/C) & 25 & 10 & Boutjdir, et al. [50] (1997) \\
\hline Ro52 & Mouse (BALB/C) & 9 & 3.6 & Miranda-Carus, et al. [53] (1998) \\
\hline Ro52 & Rabbit (New Zealand) & 9 & $\begin{array}{c}0.7 \\
\text { (20\% pups } \\
\text { born dead) }\end{array}$ & Xiao, et al. [56] (2001) \\
\hline \multirow[t]{3}{*}{ Ro52 } & Rat (DA) & 45 & 0 & Strandberg, et al. [55] (2010) \\
\hline & Rat (LEW) & 10 & 0 & \\
\hline & Rat (PVG) & 44 & 0 & \\
\hline $\operatorname{Ro} 52 \beta$ & Mouse (BALB/C) & 12 & 6 & Miranda-Carus, et al. [53] (1998) \\
\hline Ro52 (mouse) & Mouse (BALB/C) & 9 & 0 & \\
\hline Ro52 (aa 365-382) & Mouse (BALB/C) & 0 & 0 & Eftekhari, et al. [64] (2001) \\
\hline Ro52 (aa 366-379) & Mouse (BALB/C) & 0 & 0 & \\
\hline Ro52/p200 (aa 200-239) & Rat (DA) & 19 & 0 & Salomonsson, et al. [45] (2005) \\
\hline Ro60 & Mouse (BALB/C) & 19 & 0 & Miranda-Carus, et al. [53] (1998) \\
\hline Ro6 $60^{b}$ & Mouse (C3H/HEJ) & 14 & 0 & Suzuki, et al. [54] (2005) \\
\hline La & Mouse (BALB/C) & 7 & 0 & Miranda-Carus, et al. [53] (1998) \\
\hline $\mathrm{La}^{\mathrm{b}}$ & Mouse (C3H/HEJ) & 7 & 0 & Suzuki, et al. [54] (2005) \\
\hline \multirow[t]{4}{*}{ Ro52, Ro60, and La } & $\begin{array}{l}\text { Mouse (FBV Cav1.2 non-transgenic } \\
\text { littermates) }\end{array}$ & 28 & 5.5 & Karnabi, et al. [68] (2011) \\
\hline & Mouse (FBV Cav1.2 transgenic) & 9 & 1.1 & \\
\hline & Mouse (C57BL/6 Cav1.3//+) & 18 & 3 & \\
\hline & Mouse (C57BL/6 Cav1.3-1-) & 100 & 44 & \\
\hline
\end{tabular}

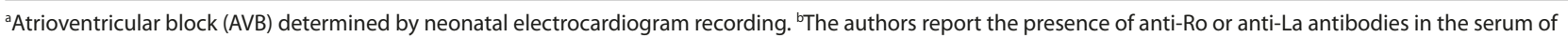
mice immunized with La or Ro60, respectively. aa, amino acids; DA, Dark Agouti.

the mechanisms at play remain unclear. The intracellular localization of the Ro52, Ro60, and La proteins, which are the major targets of maternal autoantibodies associated with heart block, has proven to be a stumbling block in the elucidation of the molecular mechanisms leading to CHB. How can the antibodies exert a pathogenic effect if their target antigens are not within their reach? Two schools of thought, not mutually exclusive and each supported by experimental data, have emerged: the 'apoptosis hypothesis' and the 'cross-reactivity hypothesis'.

\section{The apoptosis hypothesis}

The apoptosis hypothesis postulates that maternal antibodies gain access to their target antigen when it is exposed on the surface of apoptotic cells. The presence of Ro60 and La has indeed been reported on apoptotic cardiac myocytes [60]. Ro52 has also been detected on the surface of apoptotic but not live cardiac cells in one study, although only one out of the five anti-Ro52 monoclonal antibodies tested bound apoptotic cells and did so to a lesser extent than did anti-Ro60 and anti-La antibodies [61]. Programmed cell death is a physiological process that is part of the development and remodeling of organs. Under physiological conditions, apoptotic debris is removed without eliciting an inflammatory reaction. However, it is possible to envision a scenario in which maternal antibodies, entering the fetal circulation and binding to their target antigens on the surface of apoptotic cells, divert the removal of this debris from a normal non-inflammatory pathway toward its engulfment by macrophages through opsonization. Subsequent activation of the phagocytic cells may lead to production of pro-inflammatory and pro-fibrotic cytokines, recruitment of leukocytes and complement components, and 
establishment of an inflammatory reaction that will eventually irreversibly damage the targeted tissue $[48,62]$.

\section{The cross-reactivity hypothesis}

The apoptosis hypothesis cannot explain the rapid electrophysiological effects of maternal anti-Ro/La antibodies on Langendorff-perfused hearts or the specificity of the reaction in targeting the $\mathrm{AV}$ node, which remains the major and most common site of disturbances in CHB. Therefore, the cross-reactivity hypothesis suggests that maternal anti-Ro/La antibodies, or at least a subset of these, bind to cardiac membrane proteins involved in the control of electric signal generation or conduction or both, interfering with their function.

Involvement of maternal anti-Ro52 antibodies crossreacting with the serotoninergic $5-\mathrm{HT}_{4}$ receptor was suggested following the finding by Eftekhari and colleagues that antibodies to the Ro52 peptide 365 to 382 recognized residues 165 to 185 of the cardiac $5-\mathrm{HT}_{4}$ receptor [63] and that affinity-purified 5- $\mathrm{HT}_{4}$ antibodies could antagonize the serotonin-induced calcium channel activation in atrial cells [64]. However, mouse pups born to females immunized with Ro52 peptides that had been selected on the basis of recognition by anti-5- $\mathrm{HT}_{4}$ antibodies did not develop any sign of AV block or other cardiac dysfunction [64].

Boutjdir and colleagues have demonstrated that IgG purified from mothers of children with CHB inhibit Ltype and T-type calcium currents in ventricular myocytes as well as in sino-atrial node cells and exogenous expression systems [49,56,65-67]. Experimental data supporting a possible cross-reactivity of maternal anti-Ro/La antibodies with the $\alpha_{1 \mathrm{C}}$ and $\alpha_{1 \mathrm{D}}$ calcium channel subunits have been provided by the same group [66,67]. A chronic effect of maternal antibodies on the fetal heart has been proposed to be mediated by binding of antibodies to calcium channels and subsequent internalization and degradation, leading to not only inefficient signal conduction but also insufficient excitation-contraction coupling and reduction of cardiac contractile function [56]. In support of this hypothesis, mouse pups transgenic for the L-type calcium channel subunit Cav1.2 were found to develop AV block and sinus bradycardia at a lower frequency than non-transgenic littermates following in utero exposure to anti-Ro/La antibodies in an immunization model [68]. In addition, mouse pups in which the Cav1.3 subunit of the L-type calcium channel has been genetically knocked out exhibit first-degree AV block, albeit at a low frequency, and the occurrence of AV block is increased following immunization of females with the Ro and La protein before gestation [68]. Although this study does not prove that maternal anti-Ro/La antibodies directly cross-react with subunits of the L-type calcium channel, it certainly supports the hypothesis that maternal autoantibodies exert their pathogenic effects at least in part by affecting calcium homeostasis in the heart and disrupting the cardiac electric and contractile functions. Recent data generated by us provide additional evidence for such a pathogenic role of maternal autoantibodies. Using a passive transfer model of CHB, in which monoclonal antibodies are injected into pregnant rat females, we observed that only antibodies specific for the p200 domain of Ro52 induced heart block in the offspring but that antibodies targeting other domains of Ro52 did not [59]. The same p200-specific antibodies dysregulated calcium oscillations of spontaneously beating cardiomyocytes in culture. Together, these data support the hypothesis that maternal antiRo52 antibodies may cross-react with a cardiac molecule involved in calcium regulation in the heart and thus initiate cardiac conduction disturbances, detected as a first-degree AV block. It is possible that prolonged disruption of cardiac calcium homeostasis leads to increased apoptosis in the fetal heart [45], is then accompanied by exposure of the intracellular Ro and La proteins, which allows the establishment and amplification of an inflammatory reaction as described in the apoptosis hypothesis, leading to irreversible damage and complete CHB (Figure 1).

\section{Maternal and fetal factors in congenital heart block development}

The risk for $\mathrm{CHB}$ in an anti-Ro-positive pregnancy is $1 \%$ to $2 \%$, and a reported recurrence rate of $12 \%$ to $20 \%$ $[1,17,22,69]$, despite persisting maternal antibodies, indicates that additional factors (maternal or fetal or both) are critical for the establishment of heart block (Figure 2).

Genetic polymorphisms influencing fetal susceptibility to $\mathrm{CHB}$ in anti-Ro/La-positive pregnancies were first investigated in a group of 40 children with CHB by using a candidate gene approach, focusing on two known polymorphisms of the genes encoding the pro-inflammatory and pro-fibrotic cytokines tumor necrosis factor-alpha $(\mathrm{TNF} \alpha)$ and transforming growth factor-beta (TGF $\beta$ ). The TGF $\beta$ polymorphism assessed was found significantly more frequently in children with $\mathrm{CHB}$ than in their unaffected siblings, whereas the TNF $\alpha$ polymorphism studied was found at an increased frequency in both affected and non-affected children in comparison with healthy controls [70]. These findings, however, have not yet been replicated in a large group of CHB cases. More recently, Clancy and colleagues [71] performed a genome-wide association study of individuals who have $\mathrm{CHB}$ and who were born to anti-Ro/La-positive mothers. The authors reported a significant association with polymorphisms in the HLA region and at the location 21q22. Although these data need to be replicated in 


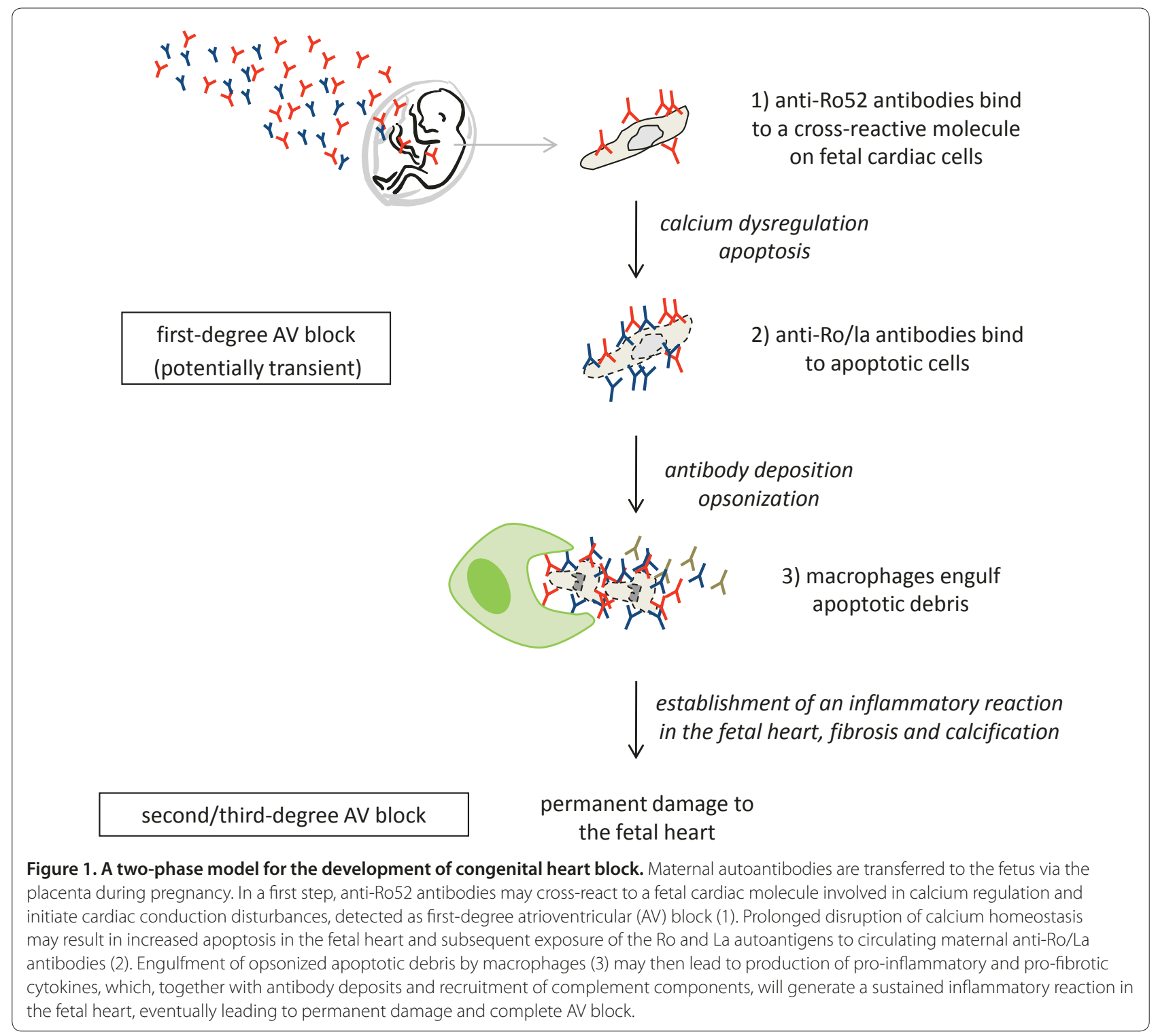

another cohort, they may provide clues for the design of functional studies addressing the pathogenic mechanisms of CHB and the role of the identified SNPs in susceptibility to CHB. However, one should be careful in the interpretation of the observed genetic associations from the case control studies, as these are performed by comparing $\mathrm{CHB}$ cases with healthy controls from the general population. Therefore, the associations may reflect simply the genetic bias present in the mothers, who may have SLE or SS or, even if asymptomatic, are genetically and immunologically distinct from the general population in terms of MHC haplotype and autoantibodies to the Ro/ La autoantigens.

Given the rarity of $\mathrm{CHB}$ in the general population, studies of genetic influences in the human disease are difficult and may not be powerful enough to identify rare variants associated with the condition. Therefore, animal models may provide another source of information, an approach used by Strandberg and colleagues [55], who recently demonstrated an influence of both maternal and fetal MHC genes in the development of CHB. Using congenic rat strains and a Ro52 immunization model of heart block, the authors showed that generation of pathogenic anti-Ro52 antibodies is restricted by maternal MHC and that the fetal MHC locus regulates susceptibility and determines the fetal disease outcome in antiRo52-positive pregnancies [55].

Maternal and fetal factors other than genetic differences have also been suggested to contribute to the development of heart block. Although neither fetal gender nor maternal disease severity has been associated with CHB [22,28], it has been proposed that maternal age 


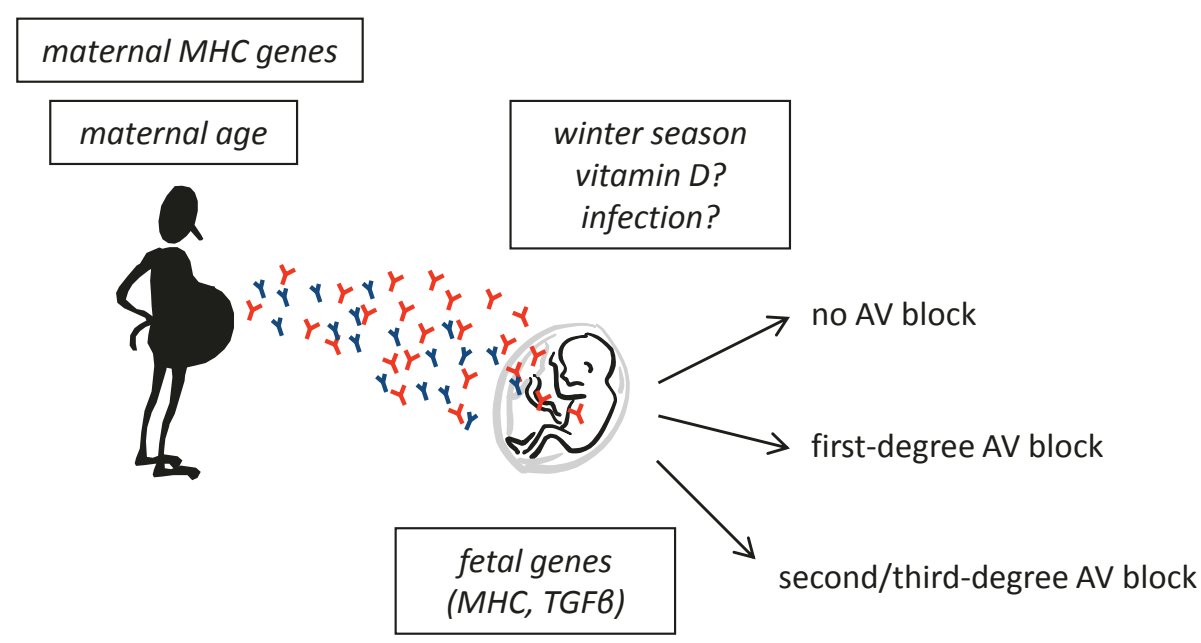

Figure 2. Maternal and fetal risk factors in congenital heart block (CHB). Environmental and genetic factors that have been implicated in the development of $\mathrm{CHB}$ to date are depicted. Whereas maternal major histocompatibility complex (MHC) genes influence the generation of autoantibodies, fetal genes influence the susceptibility of the fetal heart to the pathogenic effects of maternal antibodies. Both the age of the mother and the winter season at the time of pregnancy have recently been linked to CHB. It is possible that an increased risk for CHB with increased maternal age corresponds to the appearance of pathogenic autoantibodies. Further studies are needed to elucidate how other factors linked to age, as well as possible events linked to the winter season, may influence the risk for CHB. Low levels of vitamin D and increased rates of infection have been suggested as potential risk factors that account for the risk association with the winter season. AV, atrioventricular; TGF $\beta$, transforming growth factor-beta.

may have an influence on the outcome of anti-Ro52positive pregnancies [72]. As the number of cases included in the latter study was too small to distinguish between possible effects of maternal age and parity, we have now addressed this issue in a larger cohort. Analyzing risk factors for the development of heart block in a population-based study, we found that the risk for $\mathrm{CHB}$ increased with maternal age but was not influenced by parity [17]. Although this finding raises the possibility that age-related risk factors associated with pregnancy complications contribute to the risk of $\mathrm{CHB}$, it is also possible that the increasing risk for heart block with increasing maternal age reflects the appearance or increased serum levels of anti-Ro/La autoantibodies in women over time. Interestingly, we also found that the seasonal timing of the pregnancy influenced the outcome, and we found an increased proportion of affected pregnancies among all pregnancies for which the susceptibility weeks (18 to 24 weeks of pregnancy) took place during the late winter season in Sweden. Whereas an association between the winter season, decreased sun exposure, and vitamin D levels comes readily to mind, other events linked to the winter season, such as viral infections, may also influence the development of heart block. Indeed, maternal infections occurring during pregnancy have been suggested to play a role in $\mathrm{CHB}$, and a recent report by Tsang and colleagues [73] described cell surface exposure of the Ro antigen in fetal cardiomyocytes following cytomegalovirus infection.

\section{Conclusions}

The association of fetal/neonatal CHB with maternal anti-Ro/La antibodies is well established. Currently, however, no solid evidence regarding the pathogenesis of heart block explains the different modes of cardiac involvement and the relatively low risk for development of $\mathrm{CHB}$ in an antibody-positive pregnancy. Crossreactivity of maternal antibodies with fetal cardiac molecules regulating calcium-dependent functions in the heart may initiate conduction disturbances and cell death. Improper clearance of apoptotic debris through their opsonization by maternal antibodies and subsequent removal by macrophages may lead to a sustained inflammation in the fetal heart, eventually damaging the developing organ irreversibly. Emerging evidence implicating genetic polymorphisms and maternal factors such as age or infections in the risk for $\mathrm{CHB}$ occurrence may in time give clues about why only a small proportion of children of mothers with anti-Ro/La

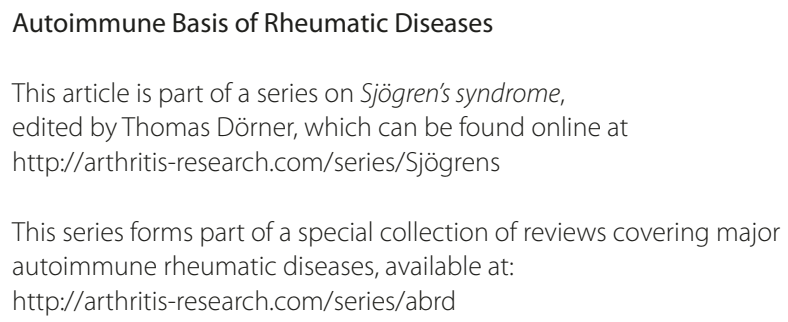


antibodies develop $\mathrm{CHB}$. Meanwhile, in the hope of developing effective therapies to prevent or treat $\mathrm{CHB}$ or both, efforts should aim at identifying better serological markers for pregnancies at risk and unraveling further the molecular mechanisms leading to CHB.

\section{Abbreviations}

5-HT 4 , 5-hydroxytryptamine; aa, amino acids; $\mathrm{AV}$, atrioventricular; $\mathrm{CHB}$, congenital heart block; MHC, major histocompatibility complex; SLE, systemic lupus erythematosus; SS, Sjögren's syndrome; TGF $\beta$, transforming growth factor-beta; TNFa, tumor necrosis factor-alpha.

\section{Competing interests}

The authors declare that they have no competing interests.

Published: 26 April 2012

\section{References}

1. Buyon JP, Hiebert R, Copel J, Craft J, Friedman D, Katholi M, Lee LA, Provost TT, Reichlin M, Rider L, Rupel A, Saleeb S, Weston WL, Skovron ML: Autoimmuneassociated congenital heart block: demographics, mortality, morbidity and recurrence rates obtained from a national neonatal lupus registry. J Am Coll Cardiol 1998, 31:1658-1666.

2. Waltuck J, Buyon JP: Autoantibody-associated congenital heart block: outcome in mothers and children. Ann Intern Med 1994, 120:544-551.

3. Eronen M, Siren MK, Ekblad H, Tikanoja T, Julkunen H, Paavilainen T: Shortand long-term outcome of children with congenital complete heart block diagnosed in utero or as a newborn. Pediatrics 2000, 106 (1 Pt 1):86-91.

4. Sonesson SE, Salomonsson S, Jacobsson LA, Bremme K, Wahren-Herlenius M: Signs of first-degree heart block occur in one-third of fetuses of pregnant women with anti-SSA/Ro 52-kd antibodies. Arthritis Rheum 2004, 50:1253-1261

5. Brucato A, Frassi M, Franceschini F, Cimaz R, Faden D, Pisoni MP, Muscarà M, Vignati G, Stramba-Badiale M, Catelli L, Lojacono A, Cavazzana I, Ghirardello A,Vescovi F, Gambari PF, Doria A, Meroni PL, Tincani A: Risk of congenital complete heart block in newborns of mothers with anti-Ro/SSA antibodies detected by counterimmunoelectrophoresis: a prospective study of 100 women. Arthritis Rheum 2001, 44:1832-1835.

6. Brucato A, Cimaz R, Catelli L, Meroni P: Anti-Ro-associated sinus bradycardia in newborns. Circulation 2000, 102:E88-89.

7. Cimaz R, Airoldi ML, Careddu P, Centinaio G, Catelli L, Franceschini F, Meroni $\mathrm{PL}$ : Transient neonatal bradycardia without heart block associated with anti-Ro antibodies. Lupus 1997, 6:487-488.

8. Gerosa M, Cimaz R, Stramba-Badiale M, Goulene K, Meregalli E, Trespidi L, Acaia B, Cattaneo R, Tincani A, Motta M, Doria A, Zulian F, Milanesi O, Brucato A, Riboldi P, Meroni PL: Electrocardiographic abnormalities in infants born from mothers with autoimmune diseases--a multicentre prospective study. Rheumatology (Oxford) 2007, 46:1285-1289.

9. Cimaz R, Stramba-Badiale M, Brucato A, Catelli L, Panzeri P, Meroni PL: QT interval prolongation in asymptomatic anti-SSA/Ro-positive infants without congenital heart block. Arthritis Rheum 2000, 43:1049-1053.

10. Costedoat-Chalumeau N, Amoura Z, Lupoglazoff JM, Huong DL, Denjoy I, Vauthier D, Sebbouh D, Fain O, Georgin-Lavialle S, Ghillani P, Musset L, Wechsler B, Duhaut P, Piette JC: Outcome of pregnancies in patients with anti-SSA/Ro antibodies: a study of 165 pregnancies, with special focus on electrocardiographic variations in the children and comparison with a control group. Arthritis Rheum 2004, 50:3187-3194.

11. Aoki H, Inamura N, Kawazu Y, Nakayama M, Kayatani F: Fetal echocardiographic assessment of endocardial fibroelastosis in maternal anti-SSA antibody-associated complete heart block. Circ J 2011, 75:1215-1221.

12. Moak JP, Barron KS, Hougen TJ, Wiles HB, Balaji S, Sreeram N, Cohen MH, Nordenberg A, Van Hare GF, Friedman RA, Perez M, Cecchin F, Schneider DS,Nehgme RA, Buyon JP: Congenital heart block: development of lateonset cardiomyopathy, a previously underappreciated sequela. J Am Coll Cardio/ 2001, 37:238-242.

13. Nield LE, Silverman ED, Smallhorn JF, Taylor GP, Mullen JB, Benson LN, Hornberger LK: Endocardial fibroelastosis associated with maternal anti-Ro and anti-La antibodies in the absence of atrioventricular block. J Am Coll Cardiol 2002, 40:796-802.
14. Nield LE, Silverman ED, Taylor GP, Smallhorn JF, Mullen JB, Silverman NH, Finley JP, Law YM, Human DG, Seaward PG, Hamilton RM, Hornberger LK: Maternal anti-Ro and anti-La antibody-associated endocardial fibroelastosis. Circulation 2002, 105:843-848.

15. Buyon JP, Kim MY, Copel JA, Friedman DM: Anti-Ro/SSA antibodies and congenital heart block: necessary but not sufficient. Arthritis Rheum 2001, 44:1723-1727.

16. Brucato A, Jonzon A, Friedman D, Allan LD, Vignati G, Gasparini M, Stein Jl, Montella S, Michaelsson M, Buyon J: Proposal for a new definition of congenital complete atrioventricular block. Lupus 2003, 12:427-435.

17. Ambrosi A, Salomonsson S, Eliasson H, Zeffer E, Skog A, Dzikaite V, Bergman G, Fernlund E, Tingström J, Theander E, Rydberg A, Skogh T, Öhman A,Lundström U, Mellander M, Winqvist O, Fored M, Ekbom A, Alfredsson L, Källberg H, Olsson T, Gadler F, Jonzon A, Kockum I, Sonesson SE, WahrenHerlenius M: Development of heart block in children of SSA/SSBautoantibody-positive women is associated with maternal age and displays a season-of-birth pattern. Ann Rheum Dis 2012, 71:334-340.

18. Villain E, Coastedoat-Chalumeau N, Marijon E, Boudjemline Y, Piette JC, Bonnet D: Presentation and prognosis of complete atrioventricular block in childhood, according to maternal antibody status. J Am Col/ Cardio/ 2006, 48:1682-1687.

19. Scott JS, Maddison PJ, Taylor PV, Esscher E, Scott O, Skinner RP: Connectivetissue disease, antibodies to ribonucleoprotein, and congenital heart block. N Engl J Med 1983, 309:209-212.

20. Taylor PV, Taylor KF, Norman A, Griffiths S, Scott JS: Prevalence of maternal Ro (SS-A) and La (SS-B) autoantibodies in relation to congenital heart block. BrJ Rheumatol 1988, 27:128-132.

21. Jaeggi ET, Hamilton RM, Silverman ED, Zamora SA, Hornberger LK: Outcome of children with fetal, neonatal or childhood diagnosis of isolated congenital atrioventricular block. A single institution's experience of 30 years. J Am Coll Cardiol 2002, 39:130-137.

22. Llanos C, Izmirly PM, Katholi M, Clancy RM, Friedman DM, Kim MY, Buyon JP: Recurrence rates of cardiac manifestations associated with neonatal lupus and maternal/fetal risk factors. Arthritis Rheum 2009, 60:3091-3097.

23. Ben-Chetrit $\mathrm{E}$, Chan EK, Sullivan KF, Tan EM: A 52-kD protein is a novel component of the SS-A/Ro antigenic particle. J Exp Med 1988, 167:1560-1571.

24. Wolin SL, Steitz JA: The Ro small cytoplasmic ribonucleoproteins: identification of the antigenic protein and its binding site on the Ro RNAs. Proc Natl Acad Sci U S A 1984, 81:1996-2000.

25. Julkunen H, Kurki P, Kaaja R, Heikkila R, Immonen I, Chan EK, Wallgren E, Friman C: Isolated congenital heart block. Long-term outcome of mothers and characterization of the immune response to SS-A/Ro and to SS-B/La. Arthritis Rheum 1993, 36:1588-1598.

26. Salomonsson S, Dorner T, Theander E, Bremme K, Larsson P, Wahren-Herlenius $\mathrm{M}$ : A serologic marker for fetal risk of congenital heart block. Arthritis Rheum 2002, 46:1233-1241.

27. Fritsch C, Hoebeke J, Dali H, Ricchiuti V, Isenberg DA, Meyer O, Muller S: 52-kDa Ro/SSA epitopes preferentially recognized by antibodies from mothers of children with neonatal lupus and congenital heart block. Arthritis Res Ther 2006, 8:R4.

28. Eronen M, Miettinen A, Walle TK, Chan EK, Julkunen H: Relationship of maternal autoimmune response to clinical manifestations in children with congenital complete heart block. Acta Paediatr 2004, 93:803-809.

29. Salomonsson S, Dzikaite V, Zeffer E, Eliasson H, Ambrosi A, Bergman G, Fernlund E, Theander E, Ohman A, Rydberg A, Skogh T, Wållberg-Jonsson S, Elfving A, Fored M, Ekbom A, Lundström U, Mellander M, Winqvist O, Sonesson SE, Gadler F, Jonzon A, Wahren-Herlenius M: A population-based investigation of the autoantibody profile in mothers of children with atrioventricular block. Scand J Immunol 2011, 74:511-517.

30. Silverman ED, Buyon J, Laxer RM, Hamilton R, Bini P, Chu JL, Elkon KB: Autoantibody response to the Ro/La particle may predict outcome in neonatal lupus erythematosus. Clin Exp Immunol 1995, 100:499-505.

31. Jaeggi E, Laskin C, Hamilton R, Kingdom J, Silverman E: The importance of the level of maternal anti-Ro/SSA antibodies as a prognostic marker of the development of cardiac neonatal lupus erythematosus a prospective study of 186 antibody-exposed fetuses and infants. J Am Coll Cardio/ 2010, 55:2778-2784

32. Gordon P, Khamashta MA, Rosenthal E, Simpson JM, Sharland G, Brucato A, Franceschini F, De Bosschere K, Meheus L, Meroni PL, Hughes GR, Buyon J: Anti-52 kDa Ro, anti-60 kDa Ro, and anti-La antibody profiles in neonatal 
lupus. J Rheumatol 2004, 31:2480-2487.

33. Orth T, Dorner T, Meyer Zum Buschenfelde KH, Mayet WJ: Complete congenital heart block is associated with increased autoantibody titers against calreticulin. Eur J Clin Invest 1996, 26:205-215.

34. Borda E, Sterin-Borda L: Autoantibodies against neonatal heart M1 muscarinic acetylcholine receptor in children with congenital heart block. J Autoimmun 2001, 16:143-150.

35. Bacman S, Sterin-Borda L, Camusso JJ, Hubscher O, Arana R, Borda ES: Circulating antibodies against neurotransmitter receptor activities in children with congenital heart block and their mothers. FASEB J 1994, 8:1170-1176.

36. Miyagawa S, Yanagi K, Yoshioka A, Kidoguchi K, Shirai T, Hayashi Y: Neonatal lupus erythematosus: maternal IgG antibodies bind to a recombinant $\mathrm{NH}$-terminal fusion protein encoded by human alpha-fodrin CDNA. J Invest Dermatol 1998, 111:1189-1192.

37. Locht H, Pelck R, Manthorpe R: Diagnostic and prognostic significance of measuring antibodies to alpha-fodrin compared to anti-Ro-52, anti-Ro-60, and anti-La in primary Sjogren's syndrome. J Rheumatol 2008, 35:845-849.

38. Ambrosi A, Strandberg L, Ottosson L, Kämpe O, Wahren-Herlenius M: AntiRo52 antibodies inducing heart block cross-react with alpha-enolase [abstract]. Arthritis Rheum 2007, 56 Suppl:S783.

39. Llanos C, Chan EK, Li S, Abadal GX, Izmirly P, Byrne C, Clancy RM, Buyon JP: Antibody reactivity to alpha-enolase in mothers of children with congenital heart block. J Rheumatol 2009, 36:565-569.

40. Karnabi E, Qu Y, Wadgaonkar R, Mancarella S, Yue Y, Chahine M, Clancy RM, Buyon JP, Boutjdir M: Congenital heart block: identification of autoantibody binding site on the extracellular loop (domain I, S5-S6) of alpha(1D) L-type Ca channel. J Autoimmun 2010, 34:80-86.

41. Kamel R, Eftekhari P, Clancy R, Buyon JP, Hoebeke J: Autoantibodies against the serotoninergic $5-\mathrm{HT} 4$ receptor and congenital heart block: a reassessment. J Autoimmun 2005, 25:72-76.

42. Blange I, Ringertz NR, Pettersson I: Identification of antigenic regions of the human $52 \mathrm{kD}$ Ro/SS-A protein recognized by patient sera. J Autoimmun 1994, 7:263-274

43. Kato T, Sasakawa H, Suzuki S, Shirako M, Tashiro F, Nishioka K, Yamamoto K: Autoepitopes of the 52-kd SS-A/Ro molecule. Arthritis Rheum 1995, 38:990-998.

44. Strandberg L, Winqvist O, Sonesson SE, Mohseni S, Salomonsson S, Bremme K, Buyon JP, Julkunen H, Wahren-Herlenius M: Antibodies to amino acid 200-239 (p200) of Ro52 as serological markers for the risk of developing congenital heart block. Clin Exp Immunol 2008, 154:30-37.

45. Salomonsson S, Sonesson SE, Ottosson L, Muhallab S, Olsson T, Sunnerhagen M, Kuchroo VK, Thoren P, Herlenius E, Wahren-Herlenius M: Ro/SSA autoantibodies directly bind cardiomyocytes, disturb calcium homeostasis, and mediate congenital heart block. J Exp Med 2005, 201:11-17.

46. Litsey SE, Noonan JA, O'Connor WN, Cottrill CM, Mitchell B: Maternal connective tissue disease and congenital heart block. Demonstration of immunoglobulin in cardiac tissue. N Eng/ J Med 1985, 312:98-100.

47. Lee LA, Coulter S, Erner S, Chu H: Cardiac immunoglobulin deposition in congenital heart block associated with maternal anti-Ro autoantibodies. Am J Med 1987, 83:793-796.

48. Clancy RM, Kapur RP, Molad Y, Askanase AD, Buyon JP: Immunohistologic evidence supports apoptosis, lgG deposition, and novel macrophage/ fibroblast crosstalk in the pathologic cascade leading to congenital heart block. Arthritis Rheum 2004, 50:173-182.

49. Boutjdir M, Chen L, Zhang ZH, Tseng CE, El-Sherif N, Buyon JP: Serum and immunoglobulin $\mathrm{G}$ from the mother of a child with congenital heart block induce conduction abnormalities and inhibit L-type calcium channels in a rat heart model. Pediatr Res 1998, 44:11-19.

50. Boutjdir M, Chen L, Zhang ZH, Tseng CE, DiDonato F, Rashbaum W, Morris A, el-Sherif N, Buyon JP: Arrhythmogenicity of IgG and anti-52-kD SSA/Ro affinity-purified antibodies from mothers of children with congenital heart block. Circ Res 1997, 80:354-362

51. Garcia S, Nascimento JH, Bonfa E, Levy R, Oliveira SF, Tavares AV, de Carvalho AC: Cellular mechanism of the conduction abnormalities induced by serum from anti-Ro/SSA-positive patients in rabbit hearts. J Clin Invest 1994, 93:718-724

52. Hamilton RM, Lee-Poy M, Kruger K, Silverman ED: Investigative methods of congenital complete heart block. J Electrocardiol 1998, 30 Suppl:69-74

53. Miranda-Carus ME, Boutjdir M, Tseng CE, DiDonato F, Chan EK, Buyon JP.
Induction of antibodies reactive with SSA/Ro-SSB/La and development of congenital heart block in a murine model. J Immunol 1998, 161:5886-5892.

54. Suzuki H, Silverman ED, Wu X, Borges C, Zhao S, Isacovics B, Hamilton RM: Effect of maternal autoantibodies on fetal cardiac conduction: an experimental murine model. Pediatr Res 2005, 57:557-562.

55. Strandberg LS, Ambrosi A, Jagodic M, Dzikaite V, Janson P, Khademi M, Salomonsson S, Ottosson L, Klauninger R, Adén U, Sonesson SE, Sunnerhagen M,de Graaf KL, Kuchroo VK, Achour A, Winqvist O, Olsson T, Wahren-Herlenius M: Maternal MHC regulates generation of pathogenic antibodies and fetal MHC-encoded genes determine susceptibility in congenital heart block. J Immunol 2010, 185:3574-3582

56. Xiao GQ, QuY, Hu K, Boutjdir M: Down-regulation of L-type calcium channel in pups born to $52 \mathrm{kDa}$ SSA/Ro immunized rabbits. FASEB J 2001 , 15:1539-1545

57. Chan EK, Di Donato F, Hamel JC, Tseng CE, Buyon JP: 52-kD SS-A/Ro: genomic structure and identification of an alternatively spliced transcript encoding a novel leucine zipper-minus autoantigen expressed in fetal and adult heart. J Exp Med 1995, 182:983-992.

58. Mazel JA, El-Sherif N, Buyon J, Boutjdir M: Electrocardiographic abnormalities in a murine model injected with lgG from mothers of children with congenital heart block. Circulation 1999, 99:1914-1918.

59. Ambrosi A, Dzikaite V, Park J, Strandberg L, Kuchroo VK, Herlenius E, WahrenHerlenius M: Anti-Ro52 monoclonal antibodies specific for amino acid 200-239, but not other Ro52 epitopes, induce congenital heart block in a rat model. Ann Rheum Dis 2012, 71:448-454

60. Miranda ME, Tseng CE, Rashbaum W, Ochs RL, Casiano CA, Di Donato F, Chan EK, Buyon JP: Accessibility of SSA/Ro and SSB/La antigens to maternal autoantibodies in apoptotic human fetal cardiac myocytes. J Immunol 1998, 161:5061-5069.

61. Clancy RM, Neufing PJ, Zheng P, O'Mahony M, Nimmerjahn F, Gordon TP, Buyon JP: Impaired clearance of apoptotic cardiocytes is linked to antiSSA/Ro and -SSB/La antibodies in the pathogenesis of congenital heart block. J Clin Invest 2006, 116:2413-2422.

62. Miranda-Carus ME, Askanase AD, Clancy RM, Di Donato F, Chou TM, Libera MR, Chan EK, Buyon JP: Anti-SSA/Ro and anti-SSB/La autoantibodies bind the surface of apoptotic fetal cardiocytes and promote secretion of TNFalpha by macrophages. J Immunol 2000, 165:5345-5351.

63. Eftekhari P, Sallé L, Lezoualc'h F, Mialet J, Gastineau M, Briand JP, Isenberg DA, Fournié GJ, Argibay J, Fischmeister R, Muller S, Hoebeke J: Anti-SSA/Ro52 autoantibodies blocking the cardiac 5-HT4 serotoninergic receptor could explain neonatal lupus congenital heart block. Eur J Immuno/ 2000, 30:2782-2790.

64. Eftekhari P, Roegel JC, Lezoualc'h F, Fischmeister R, Imbs JL, Hoebeke J: Induction of neonatal lupus in pups of mice immunized with synthetic peptides derived from amino acid sequences of the serotoninergic $5-\mathrm{HT} 4$ receptor. Eur I Immuno/ 2001, 31:573-579.

65. Xiao GQ, Hu K, Boutjdir M: Direct inhibition of expressed cardiac I- and t-type calcium channels by igg from mothers whose children have congenital heart block. Circulation 2001, 103:1599-1604.

66. Qu Y, Xiao GQ, Chen L, Boutjdir M: Autoantibodies from mothers of children with congenital heart block downregulate cardiac L-type Ca channels. J Mol Cell Cardiol 2001, 33:1153-1163.

67. Qu Y, Baroudi G, Yue Y, Boutjdir M: Novel molecular mechanism involving alpha1D (Cav1.3) L-type calcium channel in autoimmune-associated sinus bradycardia. Circulation 2005, 111:3034-3041.

68. Karnabi E, Qu Y, Mancarella S, Boutjdir M: Rescue and worsening of congenital heart block-associated electrocardiographic abnormalities in two transgenic mice. J Cardiovasc Electrophysiol 2011, 22:922-930.

69. Julkunen $\mathrm{H}$, Eronen $\mathrm{M}$ : The rate of recurrence of isolated congenital heart block: a population-based study. Arthritis Rheum 2001, 44:487-488

70. Clancy RM, Backer CB, Yin X, Kapur RP, Molad Y, Buyon JP: Cytokine polymorphisms and histologic expression in autopsy studies: contribution of TNF-alpha and TGF-beta 1 to the pathogenesis of autoimmuneassociated congenital heart block. J Immuno/ 2003, 171:3253-3261.

71. Clancy RM, Marion MC, Kaufman KM, Ramos PS, Adler A, Harley JB, Langefeld $C D$, Buyon JP: Genome-wide association study of cardiac manifestations of neonatal lupus identifies candidate loci at $6 \mathrm{p} 21$ and 21q22. Arthritis Rheum 2010, 62:3415-3424.

72. Skog A, Wahren-Herlenius M, Sundstrom B, Bremme K, Sonesson SE: Outcome and growth of infants fetally exposed to heart block-associated maternal anti-Ro52/SSA autoantibodies. Pediatrics 2008, 121:e803-809. 
73. Tsang W, Silverman E, Cui R, Bin Su B, Wu X, Hamilton R: CMV infection in cultured fetal myocytes induces cell surface expression of Ro antigen: a potential 'second hit' in the development of congenital complete heart block [abstract]. Scand J Immunol 2010, 72:262-276. doi:10.1186/ar3787

Cite this article as: Ambrosi A, Wahren-Herlenius M: Congenital heart block: evidence for a pathogenic role of maternal autoantibodies. Arthritis Research \& Therapy 2012, 14:208. 